\title{
ОПЫТ ЭКСПЛУАТАЦИИ НАРУЖНЫХ СТЕН ПОМЕЩЕНИИ С ПОВЫШЕННОЙ ВЛАЖНОСТЬЮ В ГОР. ТАЛЛИНЕ
}

\author{
Р. П. РЕИЗМАН, \\ кандидат технических наук
}

Помещения, отличающиеся повышенной влажностью вследствие особенности их назначения, к которым следует отнести бани, прачечные, а также некоторые цехи промышленных предприятий, обычно имеют неудовлетворительный вид и плохое состояние наружных стен уже после незначительного срока их эксплуатации.

Целью настоящей работы является выявление на основе конкретного материала, имеющегося в Әстонской ССР, нанболее оправдавших себя на практике конструкций стен помещений с повышенной влажностью, равно как и ошибок, допущенных строителями и проектировщиками в грошлом.

Для получения необходимых данных было пронзведено обследование существующих и эксплуатирующихся в гор. Таллине бань.

Этот вид сооружений был выбран в качестве объекта для обследования, как наиболее характерный для помещений с повышенной влажностью. Кроме того, большое количество имеющихся в наличности бань со стенами различных конструкций дает возможность произвести сравнение их, избежав в оценке пригодности конструкций ошибок, могущих пронзойти вследствие различий во внутреннем режиме. Обследованию подвергались только стены с напряженным температурно-влажностным режимом, т. е. стены мылен и парилен. (Обследование проводилось в фезрале-марте 1949 года, имевших сравнительно высокую среднюю месячную температуру.)

По типу конструкций стен существующие бани гор. Таллина можно равделить на следующие две основные группы:

a) бани с кирпичными стенами толщиной в 2,5 кирпича,

б) бани с плитняковыми (бутовыми) стенами толщиной $80-90$ см.

Почти все кирпичные стены таллинских бань выполнены из силикат. ного кирпича на известковом или сложном растворе, с незначительным добавлением цемента. Исключение составляет баня по ул. Тульби, внутренняя часть стен которой толщиной в 2 кирпича сложена из красного кирпича и облицована снаружи силикатным кирпичом толщиной в $1 / 2$ кирпича.

Внутренний пароизоляционный слой во всех банях состоит из цементной штукатурки и облицовочных плиток. Кроме того, в бане по Пярнускому шоссе, 96, был осуществлен гидроизоляционный слой из битумных материалов, прикрытый защитной стенкой из кирпича. 
В неоштукатуренных банях, сложенных с неполным заполнением швов (под штукатурку), как правило, разрушения кладки незначительны и ограничиваются выкрашиванием кромок кирпичей и появлением «выцветов». Интенсивность «выцветов» снижается по мере уменьшения заполнения швов раствором. Раствор в глубине стены сильно увлажнен и размягчен. Кладка вследствие большой продуваемости незаполненных раствором швов, очевидно, обладает бо́льшей теплопроводностью, чем это предполагалось при проектировании. Пустоты швов обычно легко прощупывались щупом на глубину $15-20$ см.

В оштукатуренных банях следует различать два типа наружных стен. Первый из них имеет наружную водопроницаемую штукатурку. К этому типу следует отнести наружные стены бани по улице Рауа, 22, внешняя поверхность которых уже через два месяца после капитального ремонта была обезображена пятнами сырости, являющимися предвестниками дальнейшего разрушения восстановленной штукатурки.

Қо второму типу относятся стены с водонепроницаемой штукатуркой. К этому типу следует отнести стены бани по улице Вальдеку, 22 (Нымме) и Вене-Балти. У этих бань цементная штукатурка отслоилась от каменной кладки, и образовавшееся пространство было заполнено льдом. Штукатурка покрыта трещинами, через которые в оттепели вытекает конденсат, образовывая сосульки, а также солевые отложения по краям трещин в виде валиков высотой 3-5 мм. Раствор кладки насыщен водой и размягчен. Силикатный кирпич, из которого сложены стены, также насыщен водой.

Особо следует рассматривать баню по улице Тульби, где наружной штукатурки нет. Стена сложена на известковом растворе и швы ее расшиты цементным тестом. В этой бане выделяющийся в стене конденсат, насытив раствор швов, стал насыщать кирпич и при замерзании отрывал наружный слой силикатного кирпича по плоскостям, отстоящим на 3 4 см от внешней поверхности стены. Значительное количество образовавшихся таким путем «четверок» кирпича можно вынуть из свонх гнезд. Кроме того, стена обильно покрыта «выцветами» слоем 5-7 мм, в виде «пуха», состоящего из белых тонких игольчатообразных кристаллов.

Бутовые стены таллинских бань, имеющих внутренний пароизоляционный слой из цементной штукатурки и облицовочных плиток, точно также, по виду внешней отделки, следует разделить на оштукатуренные снаружи и на неоштукатуренные.

Стены всех этих бань сложены из бутовой кладки. Раствор прнменялся как известковый, так и жирный сложный (Вана-Каламая, 9а). Известковый раствор швов в этом случае насыщен водой, разрушений же плитняка не наблюдалось.

Наружная штукатурка, даже выполненная из прочного сложного раствора (Вана-Қаламая, 9а), не держится и отслаивается по всей поверхности наружных стен мокрых помещений.

Наружная окраска бани по Тартускому шоссе, 83 , стены которой утеп.тены с внутренней стороны облицовкой в $1 / 2$ красного кирпича, уже через 1,5-2 месяца была обезображена разноцветными пятнами, чем подтверждается нецелесообразность произведенной покраски.

В прекрасном состоянии, несмотря на почти 50-летний период эксплуатации, находятся стены бани по улице Вееренни, выложенные из грубо околотого бута (шубы) на известковом растворе с расшивкой швов цементным тестом.

Во всех банях, сложенных из бута, за исключением бани по Вана-Қаламая, 9а, следует отметить неудачную конструкцию подоконников, не обеспечивающую надежный отвод конденсата с заполнения окон. Это 
привело к просачиванию конденсата в кладку, в результате чего бутовый камень под окнами подвергся растрескиванию и незначительному выветриванию.

В бане по Вана-Каламая, 20, замерзание конденсата в швах кладки привело к расстройству ее, выразившемуся в выдвигании отдельных камней силой замерзающей воды наружу на 7-9 см по сравнению с первоначальным их положением. Это, в свою очередь, повлекло за собой раєстройство некоторых простенков первого этажа.

В результате вышеизложенного обследования можно сделать следующие выводы:

1. Все виды наружных отделок стен мокрых помещений, как-то: штукатурки различных типов, расшивки швов и покраски, быстро выходят из строя или ухудшают теплотехнические свойства стен, и, следовательно, не должны применяться.

2. Бани из бута имеют вполне хороший внешний вид и находятся в хорошем состоянии, без значительных признаков разрушения кладки их стен.

3. Внутренняя пароизоляция из битумных материалов не предохраняет от появления «выцветов» на внешней поверхности кирпичных стен.

Ввиду отсутствия опытных данных о теплопроводности увлажненных стен в целом, а также отсутствия возможности производства измерений с целью выяснения теплопроводности и влажностного режима таких стен, были произведены аналитические расчеты.

При этом в качестве исходных были приняты данные, приведенные в табл. 1.

Т а бли и а 1

\begin{tabular}{|c|c|c|c|c|c|c|c|c|}
\hline \multirow{2}{*}{$\begin{array}{l}\text { Наименование } \\
\text { помещений }\end{array}$} & \multirow{2}{*}{$\begin{array}{c}\text { Наруж- } \\
\text { ная } \\
\text { темпе- } \\
\text { ратура } \\
t_{\mathrm{H}}\end{array}$} & \multirow{2}{*}{$\begin{array}{c}\text { Внут- } \\
\text { ренняя } \\
\text { темпе- } \\
\text { ратура } \\
\mathbf{t}_{\mathrm{BH}}\end{array}$} & \multirow[b]{2}{*}{$\mathrm{t}_{\mathrm{BH}}-\mathrm{t}_{\mathrm{H}}$} & \multicolumn{2}{|c|}{$\begin{array}{l}\text { Относительная } \\
\text { влажность \% }\end{array}$} & \multicolumn{2}{|c|}{$\begin{array}{c}\text { Давление нара } \\
\text { в мм ртутного } \\
\text { столба } \\
\end{array}$} & \multirow[b]{2}{*}{$e_{B H}-e_{B}$} \\
\hline & & & & $\begin{array}{c}\text { в } \\
\text { помещ. } \\
\omega_{\mathrm{BH}}\end{array}$ & $\begin{array}{c}\text { на } \\
\text { улице } \\
\omega_{\mathrm{H}}\end{array}$ & $\begin{array}{c}\text { в } \\
\text { помещ. } \\
\mathbf{e}_{\mathrm{BH}}\end{array}$ & $\begin{array}{c}\text { на } \\
\text { улице } \\
\mathrm{e}_{\mathrm{H}}\end{array}$ & \\
\hline $\begin{array}{l}\text { Мыльни . . : } \\
\text { Парнльни . }\end{array}$ & $-19^{*}$ & $\begin{array}{l}+30^{\circ} \\
+40^{\circ}\end{array}$ & $\begin{array}{l}49^{\circ} \\
5 y^{\circ}\end{array}$ & $\frac{75-100}{90}$ & $90 * *$ & $\begin{array}{l}28,7 \\
49,8\end{array}$ & 1,0 & $\begin{array}{l}27,7 \\
48,8\end{array}$ \\
\hline Жилые помещен & & $+18^{\circ}$ & $37^{\circ}$ & 60 & & 9,21 & & 8,21 \\
\hline
\end{tabular}

* По ОСТ 90008 - 39

** По данным, приведенным в книге К. Kirde, Andmed Eesti kliimast, 1939. а.

Для восточных районов Әстонской $\mathrm{CCP} t_{\mathrm{H}}$ понижается до $-22^{\circ} \mathrm{C}$, для западных повышается до $-17^{\circ} \mathrm{C}$.

При определении же влажностного режима стен, увлажнение которых вследствие образующегося в них конденсата происходит значительно медленнее, чем изменение температуры внутри стены (принимая во внимание, что наружная температура - $19^{\circ} \mathrm{C}$ для Таллина является кратковременным явлением), целесообразно несколько понизить наружную расчетную температуру, приняв за таковую среднюю месячную наиболее холодного месяца. Для Таллина таковой температурой будет февральская, равная $-6^{\circ}$ С по данным К. Кирде.

В результате мы будем иметь следующие-исходные данные для расчета паропроницаемости стен (см. табл. 2). 
Т а 6 лиц а 2

\begin{tabular}{|c|c|c|c|c|c|c|c|c|}
\hline \multirow{2}{*}{$\begin{array}{l}\text { Нанменование } \\
\text { помещений }\end{array}$} & \multirow{2}{*}{$\begin{array}{c}\text { Наруж- } \\
\text { ная } \\
\text { темпе- } \\
\text { ратура } \\
\text { t }_{\mathrm{H}}\end{array}$} & \multirow{2}{*}{$\begin{array}{c}\text { Внут- } \\
\text { ренняя } \\
\text { темпе- } \\
\text { ратура } \\
\text { t }_{\text {вH }}\end{array}$} & \multirow[b]{2}{*}{$t_{B H}-t_{H}$} & \multicolumn{2}{|c|}{$\begin{array}{l}\text { Относительная } \\
\text { влажность \% }\end{array}$} & \multicolumn{2}{|c|}{$\begin{array}{c}\text { Давление пара } \\
\text { мм ртутного } \\
\text { столба }\end{array}$} & \multirow[b]{2}{*}{$e_{\mathrm{BH}}-e_{\mathrm{H}}$} \\
\hline & & & & $\begin{array}{c}\text { в } \\
\text { помещ. } \\
{ }^{\omega} \mathrm{BH}\end{array}$ & $\begin{array}{c}\text { на } \\
\text { улице } \\
{ }^{\omega} \mathrm{H}\end{array}$ & $\begin{array}{c}\text { в } \\
\text { помещ. } \\
\text { e }_{\text {ВН }}\end{array}$ & $\begin{array}{c}\text { на } \\
\text { улице } \\
\text { e }_{\mathrm{H}}\end{array}$ & \\
\hline $\begin{array}{l}\text { lыльни : . } \\
\text { арильни : } \\
\text { Килые помешени }\end{array}$ & $-6^{\circ}$ & $\begin{array}{r}+30^{\circ} \\
+\quad 40^{\circ} \\
+\quad 18^{\circ}\end{array}$ & $\begin{array}{l}36^{\circ} \\
46^{\circ} \\
24^{\circ}\end{array}$ & $\begin{array}{l}90 \\
90 \\
60\end{array}$ & 90 & $\begin{array}{c}28,7 \\
49,8 \\
9,21\end{array}$ & 2,8 & $\begin{array}{c}25,9 \\
47,0 \\
6,14\end{array}$ \\
\hline
\end{tabular}

Из этого сопоставления видно, что наружные стены мокрых помещений находятся под воздействием значительно бо́льших разностей температур и парциальных давлений водяного пара, чем стены обычных помещений. Все это способствует конденсированию внутри стены водяных паров, проникших в нее из помещений, и изменению теплотехнических и физических свойств стены и составляющих ее материалов. Обычно это изменение теплотехнических и физических свойств в расчетах не учитывается, хотя вносит значительные погрешности в конечные результаты.

Свойства некоторых материалов стен, в зависимости от их влажности, характеризуются данными, приведенными в табл. 3.

Т а бли ц а 3

\begin{tabular}{|c|c|c|c|c|c|c|}
\hline \multirow[b]{2}{*}{ Наименование } & \multicolumn{4}{|c|}{ При естественной влажности } & \multicolumn{2}{|c|}{$\begin{array}{l}\text { При насыщении } \\
\text { водой }\end{array}$} \\
\hline & $\begin{array}{c}\text { Объем- } \\
\text { ный } \\
\text { вес } \\
\gamma \frac{\mathbf{k r}}{\mathbf{m}^{\mathbf{a}}}\end{array}$ & $\mid$\begin{tabular}{c|} 
Коэффн- \\
циент тепло- \\
проводности \\
$\lambda \frac{\text { ккал }}{\text { м час грал. }} \mid$
\end{tabular} & $\left|\begin{array}{c}\text { Коэффи- } \\
\text { циент паро- } \\
\text { проницаемо- } \\
\text { сти } \\
\frac{\text { гр }}{\text { м часмм рт.ст. }}\end{array}\right|$ & $\begin{array}{c}\text { Весо- } \\
\text { вая } \\
\text { влаж- } \\
\text { ность } \\
\%\end{array}$ & $\begin{array}{c}\text { Коэффи- } \\
\text { циент тепло- } \\
\text { проводности } \\
\lambda \frac{\text { ккал }}{\text { м час град. }}\end{array}$ & $\begin{array}{c}\text { Весо- } \\
\text { вая } \\
\text { влаж- } \\
\text { ность } \\
\%\end{array}$ \\
\hline Цементная штукатурка & & & & & & \\
\hline $\begin{array}{c}1: 4 \\
\text { Кирпич красный }\end{array}$ & $1800^{1}$ & $\begin{array}{l}0,8^{1} \\
071\end{array}$ & $0,022^{1}$ & 2,5 & $0,9^{3}$ & $15^{3}$ \\
\hline Кирпич силикатный & $1900^{2}$ & $0,9^{2}$ & $0,014^{1}$ & $\begin{array}{l}2,5 \\
2,5\end{array}$ & $\begin{array}{l}0,95^{3} \\
1,15^{3}\end{array}$ & $\begin{array}{l}15^{3} \\
10^{2}\end{array}$ \\
\hline $\begin{array}{l}\text { Камень бутовый из } \\
\text { карьера Ласнамяэ . }\end{array}$ & $2600^{4}$ & $1,9^{4}$ & $0,0026^{4}$ & 0,5 & $2,0^{4}$ & $1,5^{4}$ \\
\hline $\begin{array}{l}\text { Три слоя рубероида с } \\
\text { промазкой битумом }\end{array}$ & $600^{1}$ & $0,15^{1}$ & $33,9^{1}$ & - & - & - \\
\hline $\begin{array}{c}\text { Кладка бутовая на це- } \\
\text { ментном растворе }\end{array}$ & $2400^{4}$ & $1,50^{4}$ & $0,0065^{4}$ & 0,3 & $1,60^{4}$ & - \\
\hline
\end{tabular}

Прим е ч ания:

1 По данным, приведденным в книге Л. А. Серка, Архитектура гражданских и промышленных зданий, том II, Стройиздат, Москва, 1948.

2 По данным, опубликованным в книге проф. О. Маддисона, Технические качества искусственных камней Эстонии, 1939.

з Бычислено по данным, приведенным в книге А. У. Франчука, Теплопроводность строительных материалов в зависимости от влажности, 1941.

4 По определениям автора.

Расчет стен производился, как обычно, путем вычисления коэффициента теплопередачи К по формуле

$$
K=\frac{1}{\frac{1}{\alpha_{\mathrm{BH}}}+\Sigma \frac{\delta}{\lambda}+\frac{1}{\alpha_{\mathrm{H}}}},
$$


где $\alpha_{\text {вн }}-$ коэффициент тепловосприятия, $\alpha_{\text {н }}$ - коэффициент теплоотдачи, $\delta$ - толщина слоя стены и $\lambda$ - коэффициент теп̆лопроводности материала стены, и сопротивления паропроницаемости по формуле

$$
H=\Sigma \frac{\delta}{\mu},
$$

где $\delta$ - толщина слоя стены и $\mu$ - коэффициент паропроницаемости материала стены.

В качестве примера рассмотрены расчеты следующих типов наружных стен, часто встречающихся в банях гор. Таллина:

1. Стены, сложенной из силикатного кнрпича, толщиной 64 см, оштукатуренной с внутренней стороны цементным раствором.

2. Бутовой стены толщиной 60 см, облицованной с внутренней стороны красным кирпичом и оштукатуренной цементным раствором.

3. Бутовой стены толщиной 90 см, оштукатуренной с внутренней стороны цементным раствором.

4. Қирпичной стены толщиной 64 см, имеющей с внутренней стороны трехслойный гидроизоляционный ковер из руберойда, с промазкой битумом, защищенной с внутренней стороны стенкой толщиной в $1 / 2$ кирпича н цементной штукатуркой.

Произведя вычисление коэффициента общей теплопередачи стены и сопротивления паропроницаемости стены обычными методами, получаем следующие физические характеристики стен (см. табл. 4).

Та блица 4

\begin{tabular}{|c|c|c|c|c|}
\hline \multirow[b]{2}{*}{$\begin{array}{l}\text { Наименование } \\
\text { конструкций }\end{array}$} & \multicolumn{2}{|c|}{ Сухая стена } & \multicolumn{2}{|c|}{ У влажненная стена } \\
\hline & $\begin{array}{c}\text { Коэффициент } \\
\text { теплопереда чи } \\
\text { стены } \\
\text { К } \frac{\text { ккал }}{\text { час } \text { м² град. }^{2}}\end{array}$ & $\begin{array}{c}\text { Сопротивле- } \\
\text { ние паропро- } \\
\text { ницаемости } \\
\text { H } \frac{\text { мм час м² }}{\text { грамм }}\end{array}$ & $\begin{array}{l}\text { Коэффициент } \\
\text { теплопередачи } \\
\text { стены } \\
\text { К } \frac{\text { ккал }}{\text { час } \mathrm{M}^{2} \text { грал. }}\end{array}$ & $\begin{array}{c}\text { Величина К } \\
\text { в \% по отно- } \\
\text { шению к } \\
\text { сухой стене }\end{array}$ \\
\hline $\begin{array}{l}\text { Стена толщиной } 64 \text { см } \\
\text { из силикатного кир- } \\
\text { пича с внутренней } \\
\text { цементной штука- } \\
\text { туркой } \\
\text { Бутовая стена толщи- } \\
\text { ной } 60 \text { см с обли- } \\
\text { цовкой красным } \\
\text { кирпичом и цемент- } \\
\text { ной штукатуркой } \\
\text { Бутовая стена толщи- } \\
\text { ной } 90 \text { см с шемент- } \\
\text { ной штукатуркой } \\
\text { Кнрпичная стена с } \\
\text { гидроизоляционным } \\
\text { ковром и цементной } \\
\text { штукатуркой общей } \\
\text { толщиной в } 3 \text { кнр- } \\
\text { пича }\end{array}$ & 1,23 & 151,7 & 1,31 & 120 \\
\hline
\end{tabular}

Построив графики распределения температур и давлений водяного пара в толще стены, легко обнаружить, что в первых трех типах стен будет пронсходить конденсирование водяных паров в пределах почти всей толщи стены. В стене же с внутренней гидроизоляцией выпадение кон- 
денсата будет происходить только во внутреннем облицовочном слое стены, вся же основная толща ее будет оставаться в сухом состоянии.

В результате ряда наблюдений над существующими сооружениями установлено, что конденсат весьма быстро распространяется по всей толще стены и, испаряясь на наружной ее поверхности в атмосферу, способствует появлению регулярного потока влаги, хотя и медленного, от внутренней поверхности стены к наружной.

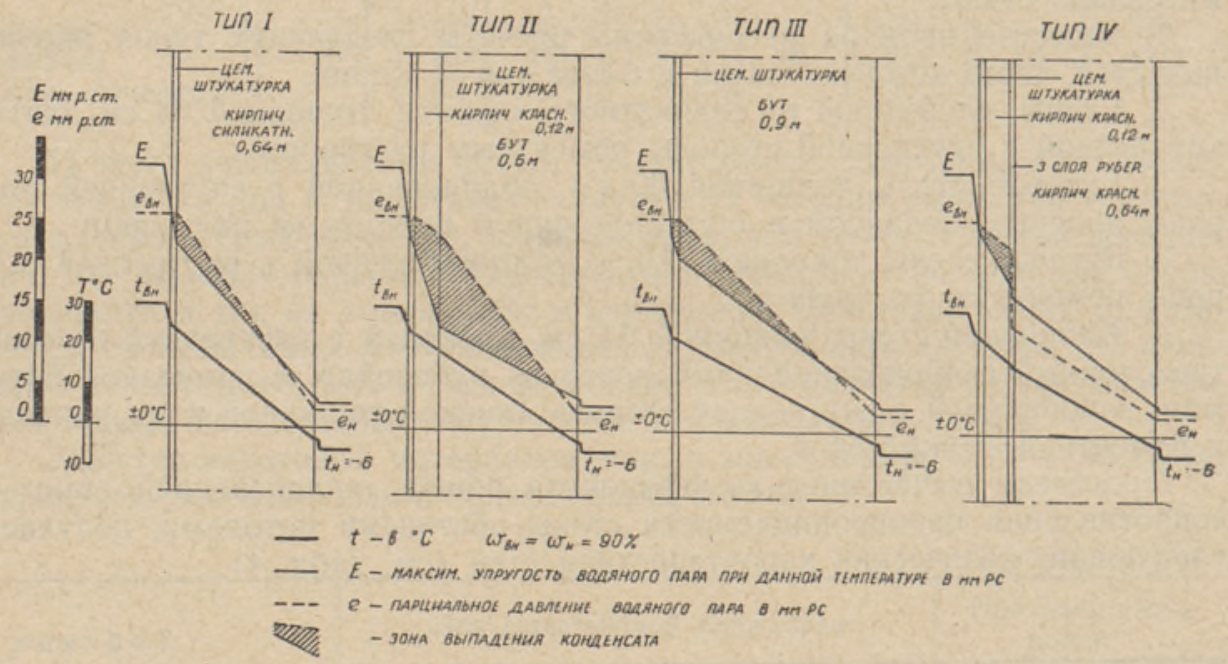

Рис. 1

Паропроницаемость увлажненных стеновых материалов сильно уменьшается, причем значительно возрастает их теплопроводность. Кроме того, конденсат, замерзая в зимнее время в порах наружного слоя стены, еще более увеличивает его теплопроводность, почти полностью прекращает дальнейшее испарение влаги в атмосферу, способствует дальнейшему увлажнению стены и вызывает при замораживании усиленное разрушение ее поверхностного слоя.

Таким образом, интенсивное увлажнение наружных стен бань обычной конструкции, подтверждаемое как расчетами, так и наблюдениями и доходящее иногда до полного насыщения их влагой, влечет за собой значительное ухудшение теплотехнических свойств наружных ограждений.

(Коэффициенты теплопередачи, вычисленные для увлажненных стен, помещены в вышеприведенной табл. 4).

Из вышеизложенного можно сделать заключение, что:

1) при расчетах стен помещений с повышенной влажностью на теплопроводность необходимо учитывать повышение теплопроводности материалов вследствие их увлажнения;

2) теплопроводность стен, выполненных из более пористого материала, каким является кирпич, при увлажнении значительно увеличивается. Это увеличение достигает 20-25\% и должно быть компенсировано увеличением толщины стены. Теплопроводность стен, выпслненных из малопористого материала (бута), увеличивается при увлажнепии значительно меньше и поэтому практически не требуется увеличивать толщину таких стен свыше обычной нормы, особенно если учитывать их большую теплоемкость; 
3) гидроизоляционный ковер из битумных материалов не является надежной пароизоляцией и даже при кратковременных повышениях относительной влажности внутри помещения свыше $90 \%$ (практически в банях наблюдается относительная влажность 95 и $100 \%$ ) не может надежно предохранить наружную часть стены от увлажнения конденсиругщимися водяными парами и наружную поверхность стены от появления «выцветов».

Суммируя результаты наблюдений и аналитических расчетов, следует прийти к следующим окончательным выводам:

1. Стены мокрых помещений при применении обычных конструкций будут находиться в сильно увлажненном состоянии. Вследствие этого их теплопроводность будет больше проектируемой, а, следовательно, толщина их на практике окажется недостаточной.

2. Наружные штукатурки и окраски являются излишними и не только не способствуют улучшению внешнего вида сооружений рассматриваемого типа, но даже ухудшают его и, кроме того, часто снижают теплозащитные свойства стен.

3. При желании предотвратить появление «выцветов» на наружной поверхности стен и сохранить ее сухой необходимо устройство надежного парогидроизоляционного ковра по внутренней поверхности стен, определяя толщину его с учетом необходимого коэффициента запаса. При расчете следует принимать относительную влажность в мыльнях и парильнях не менее $98 \%$ и коэффициент запаса не менее 1,1 . Устройство подобного ковра из битумных рулонных материалов толщиной в 5-6 слоев чрезвычайно сложно и может быть рекомендовано только в исключительных случаях. В порядке предложения можно рекомендовать устройство пароизоляционного ковра путем оклеивания стены, подготовленной цементным раствором, алюминиевой фольгой с устройством защитной стенки из кирпича на цементном растворе.

4. В условиях Северной Әстонии и гор. Таллина представляется целесообразным выкладывать наружные стены мокрых помещений из бутовой плиты толщиной 100-110 см, причем внутреннюю версту класть на цементном жирном растворе, а наружную на тощем сложном, для облегчения испарения влаги из стены. Наружную отделку при этом рекомендуется выпіолнять из грубо отесанного камня. В ряде случаев это может оказаться более выгодным и обеспечить лучший вид сооружения.

5. При ремонте существующих зданий целесообразно, если это возможно, наружную штукатурку не восстанавливать. При необхсдимости же восстановления таковой можно рекомендовать наносить ее тиркретированием с оставлением 30-50\% площади стены неоштукатуренной, с целью обеспечения возможности испарения влаги из стены. В исключительных случаях, при необходимости обеспечить хороший внешний вид здания можно применить штукатурку по сетке «Рабитца», укрєпленной на относе. Образующийся воздушный прослоек должен иметь ширину не менее $7-8$ см и сообщаться достаточным количеством вентиляционных отверстий с наружной атмосферой. Облицовка фасадов бань камнем должна также производиться с оставлением вентилируемого воздушного промежутка.

6. Во всех случаях необходимо обращать внимание на обеспечение надежного отвода конденсата́ с остекления оконных проемов путем устройства наклонных цементных подоконников и прокладывания под ними рулонной гидроизоляции. Уклон подоконников должен обеспечивать быстрый сток конденсата. 
Перечень бань гор. Таллнна с плитняковымн стенами

\begin{tabular}{|c|c|c|c|c|}
\hline $\begin{array}{c}\text { Наименование } \\
\text { бань }\end{array}$ & $\begin{array}{c}\text { Конструкщия } \\
\text { стен }\end{array}$ & $\begin{array}{l}\text { Внутренняя } \\
\text { отделка }\end{array}$ & $\begin{array}{l}\text { Наружная } \\
\text { отделка }\end{array}$ & Разрушение \\
\hline $\begin{array}{c}\text { Вана-Қаламая, } \\
\text { 9-а, } 1929 \text { г. }\end{array}$ & $\begin{array}{l}\text { Бутовые тол- } \\
\text { щин. } 90 \text { см на } \\
\text { цементном } \\
\text { растворе }\end{array}$ & $\begin{array}{l}\text { Штукатурка, } \\
\text { облицовка } \\
\text { плиткой }\end{array}$ & $\begin{array}{c}\text { Штукатурка } \\
\text { сложным } \\
\text { раствором }\end{array}$ & $\begin{array}{l}\text { Наружная штукатурка } \\
\text { отвалилась на 75\% } \\
\text { площади стен мокрых } \\
\text { помещений }\end{array}$ \\
\hline $\begin{array}{l}\text { Вана-Каламая, } \\
20\end{array}$ & $\begin{array}{l}\text { Tо же, на из- } \\
\text { вестковом } \\
\text { растворе }\end{array}$ & ", & " & $\begin{array}{l}\text { Под частью оконных про- } \\
\text { емов расстроена клад- } \\
\text { ка вследствие просо- } \\
\text { чнвшегося в нее кон- } \\
\text { денсата. Разрушение } \\
\text { наружной штукатурки }\end{array}$ \\
\hline $\begin{array}{c}\text { Вееренни, } 22, \\
1890 \text { г. }\end{array}$ & То же, $90 \mathrm{~cm}$ & " & \begin{tabular}{|l|} 
Плитняк \\
грубо ско- \\
лотый \\
(шуба)
\end{tabular} & $\begin{array}{l}\text { Незначительное вывет- } \\
\text { ривание кладки под } \\
\text { окнами мокрых поме- } \\
\text { щений, «Выцветов» } \\
\text { нет. Общее состояние } \\
\text { хорошее }\end{array}$ \\
\hline $\begin{array}{l}\text { Тартуское шос- } \\
\text { се, } 83,1881 \text { r. }\end{array}$ & $\begin{array}{l}\text { Бутовые с обли- } \\
\text { цовкой внутри } \\
\text { кирпичом }\end{array}$ & " & $"$ & $\begin{array}{l}\text { В районе мокрых поме- } \\
\text { щений на стенах обиль- } \\
\text { ные пятна разных цве- } \\
\text { тов. }\end{array}$ \\
\hline
\end{tabular}

В ы в о д. Лучшей стеной является бутовая стена на цементном растворе без наружной штукатурки. Кладка на сложном и известковом растворах способствует появлению «выцветов». Нанесение наружной штукатурки является ошибкой.

Ннститут строительства и архитектуры

Академии Наук Эстонской ССР 